\title{
D. W. WINNICOTT: \\ LO POSITIVO DE LA AGRESIVIDAD Y EL ODIO EN EL DESARROLLO TEMPRANO Y EN EL TRATAMIENTO
}

Adriana Anfusso

Licenciada en Psicología de la UDELAR Miembro Habilitante de la AUDEPP

Profesora adjunta del IUPA

Miembro del Board Latinoamericano de los Encuentros Winnicott Correo electrónico: adriana.anfusso@gmail.com ORCID: 0000-0002-8744-432X

Laura de Souza

Licenciada en Psicología de la UCU Miembro Habilitante de la AUDEPP

Profesora titular del IUPA

Miembro del Board Latinoamericano de los Encuentros Winnicott Correo electrónico: Idesouza.56@gmail.com ORCID: 0000-0003-3189-7677 


\section{Resumen}

El objetivo de este trabajo es explorar los aspectos positivos y negativos de la agresividad, el odio y sus derivados tal como aparecen en la obra de Winnicott. Examinaremos su origen y naturaleza, sus opuestos y algunos conceptos que les son afines. También consideraremos la ineludible influencia que este autor les atribuye en el desarrollo humano y en la psicoterapia psicoanalítica de pacientes que sufrieron traumas tempranos y agonías primitivas en las primeras etapas de su vida.

Palabras clave: agresividad, odio, desarrollo, terapia psicoanalítica

\section{W. WINNICOTT: THE POSITIVE ASPECTS OF AGGRESSIVENESS AND HATE IN EARLY DEVELOPMENT AND IN TREATMENT}

\section{Abstract}

Our aim is to explore the positive and negative aspects of aggressiveness, hate and its derivatives that are present in Winnicott's work. We will examine their origin and nature as well as those of some opposite terms and related elements. In addition we will consider the unavoidable influence this author attributes to these aspects in human development and in the psychoanalytical treatment of patients that experienced early traumas and primitive agonies in the first stages of life.

Keywords: aggressiveness, hate, development, psychological therapy 
El odio es uno de los malos sentimientos que solemos experimentar, aunque en general nos es difícil aceptarlo como propio. La moral lo ha vuelto un concepto no demasiado relevante, incómodo y bastante mal visto en general y por cada uno de nosotros, tengamos o no formación religiosa.

En este artículo nos cuestionamos acerca del odio, uno de los derivados de la agresividad que suele incluirse dentro de la categoría de esos malos sentimientos. Nuestra intención es examinar su naturaleza y origen, sus opuestos, algunos conceptos que le son afines y las funciones que se le asignan en ciertos desarrollos de la teoría y la técnica psicoanalítica.

Nos referimos a los aportes de Donald Woods Winnicott, autor que mostró profundo interés por estos temas a lo largo de toda su vida y que produjo una serie de trabajos importantes, si bien complejos, al respecto. Entre sus producciones más conocidas se cuentan La agresión y sus raíces, de 1939, El odio en la contratransferencia, de 1947, La contratransferencia, de 1960, Agresión, culpa y reparación, de 1960, y El uso de un objeto y la relación por medio de identificaciones, de 1968. En ellas reserva un sitio particularmente destacado para la agresividad y el odio, a los que reivindica con sólidos y reiterados argumentos y les adjudica un lugar positivo e insoslayable en la vida y en el psicoanálisis, en la salud y en la patología.

Winnicott es hoy uno de los pensadores psicoanalíticos más valorados en Occidente. Se trata de un siempre agudo teórico y clínico que inevitablemente provoca divergencias cuando se lo trata de categorizar. Es posible reconocer su sensatez y respeto hacia las verdades instaladas, pero casi en simultáneo se lo advierte confrontando, desobedeciendo, incluso provocando al statu quo. Por ejemplo, por 1947, época en la que se 
pregonaban con firmeza los valores de la neutralidad y la abstinencia, Winnicott eligió un título casi desafiante para uno de sus artículos. Nos referimos a su bien conocido texto El odio en la contratransferencia. El pensamiento paradójico y complejo es una marca que lo distingue permanentemente y que está presente en toda su obra y más visiblemente en sus teorizaciones en torno a la agresividad y el odio, que siguen prestándose, hoy como ayer, a discusiones nunca clausuradas.

Con su planteo dialéctico, Winnicott superó las dicotomías —que él siempre consideró falsas - entre sujeto y objeto, individuo y sociedad, heredado y adquirido, fantasía y realidad... Su particular forma de ver las cosas le exigía interrelacionar áreas y conceptos hasta ese momento clivados. Así es que propuso al psicoanálisis complementar el examen del individuo como un aislado con el examen de un nuevo objeto de estudio, también paradojal y complejo: la unidad dual individuo-ambiente, cuya primera versión es la díada madre-bebé, a la que luego sumó la dupla paciente-terapeuta.

Para empezar, consignamos que muy tempranamente Winnicott (1990a) advierte que

Basta observar al ser humano adulto, al niño o al bebé, para comprobar que el amor y el odio existen en ellos. [...] De todas las tendencias humanas, la agresividad, en particular, está oculta, disfrazada, desviada, se la atribuye a factores externos y cuando aparece siempre resulta difícil rastrear sus orígenes. (p. 104)

Winnicott revisó ampliamente las versiones de Sigmund Freud (1991) y Melanie Klein (1980) acerca de la agresividad y el odio. Lo hizo particularmente a partir de su experiencia con pacientes llamados graves o inanalizables, de donde surgió su personal idea de que, particularmente en esos casos, es posible concebir un cierto paralelismo entre la crianza y el 
tratamiento terapéutico. De allí también nació su visión de la agresividad y el odio como ingredientes insoslayables de la naturaleza humana, a la que aportan elementos positivos que Winnicott se esforzó por señalar y describir pese a la postura oficial adversa del psicoanálisis de su época. Con esta y muchas otras propuestas innovadoras, Winnicott contribuyó de forma importante a los significativos procesos de cambio que empezaron a darse en la teoría y en la práctica psicoanalíticas ya a mediados del siglo xx, cambios que continúan hasta el momento actual y que seguirán dándose en tanto nuestra disciplina se mantenga realmente viva.

A continuación, examinaremos con atención qué pasa con el odio en el desarrollo normal y en el proceso terapéutico de casos considerados dificiles, dos áreas que Winnicott visualiza con ciertos paralelismos y entrelazamientos. Es en base a elementos teóricos y ejemplos clínicos que justifica el papel protagónico y positivo que asigna a la agresividad y al odio, y que le interesa destacar (Winnicott, 1991c).

Discrepa con la clásica propuesta dualista que opone al instinto de vida el instinto de muerte, planteados ambos como de carácter innato, propuesta que él asocia con el concepto de pecado original que siempre rechazó terminantemente. Para dar cuenta de los orígenes de la agresividad y desde una postura monista, Winnicott (1991c) postula, en cambio, una fuerza vital inicial constructivo-destructiva a la que también se refiere con los términos paradojales de amor-discordia, amor-lucha o amor-odio. Tal fuerza vital —al igual que el viento, el agua o el fuego- conlleva posibilidades constructivas, creativas y provechosas, junto a otras destructivas, devastadoras, negativas. Interesa destacar que cuando observa al recién nacido la reconoce en su voracidad y en su irrefrenable tendencia al movimiento.

Winnicott (1991c) considera al movimiento como expresión de vida, por lo que sostiene que un bebé que patea, grita, araña o muerde no lo hace en base a su agresividad innata, sino porque está vivo y ejercita sus 
funciones. Plantea que la forma más primitiva de amor incluye naturalmente lo agresivo, pero aclara que en esos tiempos se trata de un amor precruel, aparentemente despiadado o incompasivo y que potencialmente puede causar daño, aunque no lo impulsa intención agresiva alguna. Entre otras cosas, porque un bebé inmaduro no está en condiciones de concebir un blanco al que apuntar. Deberá recorrer un buen trecho para alcanzar la discriminación, el concepto de exterioridad y la noción de un otro a quien agredir.

Según Winnicott (1991b, 1999b), el odio recién aparece cuando culmina la primera etapa del desarrollo, cuando el infante abandona la dependencia absoluta y supera la vivencia de omnipotencia absoluta, que según el autor se extiende hasta cerca del primer año de vida. Poco a poco, el infans va adquiriendo grados cada vez mayores, aunque nunca absolutos, de independencia. Su voracidad (mouth-love), hasta entonces concebida por él como todopoderosa, encuentra un límite cuando, una y otra vez, el pecho que cree haber vaciado absolutamente reaparece lleno de leche. Al sobrevivir incólume, ese pecho volvedor se convierte en el primer tú del bebé, da entrada a la primera noción de lo que no forma parte del todo grandioso, con poderes mágicos, que el bebé cree ser. Winnicott pone el nombre de not-me a esta nueva categoría de objetos y eventos que el bebé empieza a reconocer.

Las traducciones de la obra de Winnicott que conocemos no trasladan al español la diferencia teórica entre not-me y not-I. Ambas se homologan erróneamente en un no-yo, pero lo cierto es que con el giro not-me Winnicott introduce el antecedente evolutivo de lo not-I. Lo not-me corresponde al período en el que el bebé empieza a salir de la etapa de dependencia absoluta, cuando la vivencia de fusión y de omnipotencia comienza a desvanecerse; es decir, al pasaje de la dependencia absoluta a la dependencia relativa. Si bien muchas situaciones se siguen resolviendo exactamente a la manera del bebé gracias al manejo suficientemente 
bueno de quienes lo cuidan, que responden haciendo caso exactamente a sus necesidades, el bebé empieza a captar que algunos hechos, objetos o situaciones se le resisten, parecen tener vida propia e independiente de él. Sería el caso del pecho volvedor que recién planteamos. Todo eso que percibe como rebelde sería colocado por el bebé dentro de la categoría de lo not-me, que empieza a constituirse y a prefigurarse como antecedente de lo not-I o no-yo propiamente dicho. Se trata de un momento estructurante, previo a ese otro más definitorio aun, en el que se estrenan y adquieren sentido nada menos que lo interno y lo externo, y en que se instalan las nociones del yo, del otro, del tú...

Al conformarse los espacios diferenciados de lo interno y lo externo, el niño pequeño puede también empezar a distinguir y separar la realidad fáctica de la realidad propia de la fantasía.

Las ideas y la conducta agresivas adquieren un valor positivo comparadas con la destrucción mágica, en tanto que el odio se transforma en una señal de civilización. (Winnicott, 1990b, p. 120)

Con el tiempo [...] los bebés adquieren el impulso de morder. Esto marca el comienzo de algo muy importante, que pertenece al área de la crueldad, el impulso o el uso de objetos desprotegidos. [...] tarea de las madres es protegerse sin tomar represalias ni vengarse [...], sobrevivir [...]. Si ella sobrevive el bebé hallará un nuevo significado para la palabra amor, y en su vida aparecerá algo nuevo, que es la fantasía. Es como si ahora el bebé pudiese decirle a su madre: «Te quiero porque has sobrevivido a mis intentos de destruirte. En mis sueños y en mi fantasía te destruyo cada vez que pienso en ti, porque te quiero». Esto es lo que objetiviza a la madre, la sitúa en un mundo que no es parte del bebé y la torna útil. (Winnicott, 1989, p. 51) 
Integrando su experiencia pediátrica y psicoanalítica, Winnicott (1990b) afirma: «Los bebés no recuerdan haber recibido un sostén adecuado: lo que recuerdan es la experiencia traumática de no haberlo recibido» (p. 87). Considera que los bebés que han resultado traumatizados por haber sufrido rupturas excesivas de la continuidad de su existencia en épocas tempranas experimentan lo que ha dado en llamar angustias o agonías impensables, producto del derrumbamiento de su precario yo en construcción (Winnicott, 1991a). Estas angustias son homólogas a la sensación de fragmentarse en mil pedazos, de caer para siempre y nunca dejar de caer, de perder absolutamente la conexión con el cuerpo u otras situaciones equivalentes. Los adultos que han pasado por estas circunstancias y luego consultan suelen armar en los consultorios reediciones esperanzadas de aquellas fallas traumáticas originarias, reediciones que vendrán acompañadas de ataques al encuadre de todo tipo a los que el analista deberá sobrevivir. El terapeuta que sobrevive es el que permanece en su función sin mayores cambios, se mantiene lo más parecido a sí mismo que le es posible y no toma represalias. Solo así se puede promover la cura y auspiciar lo que Winnicott (1999c) considera un nuevo comienzo que destrabará el desarrollo detenido o desviado originado por fallas tempranas de quienes cumplían las funciones parentales. El bebé debió reaccionar, renunciar a sus respuestas espontáneas para encajar en el lecho de Procusto que le ofrecieron cuidadores que no fueron capaces de adivinar sus necesidades. La adaptación, el sometimiento y las defensas falso self remplazaron desde entonces la espontaneidad propia de la conducta que define a la infancia normal.

Winnicott (1993a) reconoce que en la práctica clínica se dan situaciones en las que el rol profesional se ve alterado debido a la emergencia de aspectos personales del analista de difícil manejo, como eventuales sentimientos de odio. En tales casos, tanto Winnicott como Margaret Little consideran de suma importancia que el analista acepte el surgimiento de 
esas reacciones imprevisibles, de origen consciente o inconsciente, que a menudo responden al impacto que producen en él actitudes inesperadas o regresivas de los pacientes (Little, 1995). Así es que se populariza el concepto de respuesta total del analista (R) acuñado por Little en 1957, que era colega y paciente de Winnicott, quien valora y hace suya tal denominación. Esta R incluye «todo lo que el analista hace, piensa, imagina, sueña o siente en relación a su paciente, a lo largo de todo el análisis» (Little, 2017, pp. 215-216). Winnicott y Little acuerdan en cuanto a que la neutralidad no solo es imposible de sostener, sino que además no resulta deseable. Conciben al analista como alguien fuertemente comprometido con su trabajo y con su paciente, e inevitablemente atravesado por las múltiples y variadas complejidades propias de su irrenunciable subjetividad. Esta subjetividad solo se podrá controlar muy parcialmente, por más y mejor analizado que se esté, y además incluye, obviamente, agresividad y odio latentes, que inevitablemente aflorarán cada tanto con mayor o menor visibilidad y fuerza. En tales casos, el analista tendrá que hacerse cargo de ello, reconocerlo e incluso disculparse.

En todo análisis son inevitables ciertas fallas del analista. Carece de importancia que estas sean reales, fantaseadas o atribuidas y proyectadas en el analista por el paciente. No importa si es justa la atribución o si el paciente adjudica esa falla equivocadamente, porque en ambos casos la situación es vivida por ese paciente como absolutamente real, ya que hay momentos en que realidad y fantasía se confunden. El paso siguiente es que el terapeuta integre el tema en la sesión para ofrecer la oportunidad de trabajar en torno a la coexistencia de distintas verdades que dependen de la subjetividad de cada uno y que hay que aprender a reconocer, tolerar y respetar. Una actitud tal del terapeuta permite al paciente revivir y reubicar la perspectiva de aquella vivencia traumática que fue parte de lo sabido no pensado (Bollas, 1991) y que afectó su desarrollo desde su primera infancia. Aspectos que el paciente concebía como incambiables 
e inherentes a su ser dejan de serlo y pasan a ser considerados como el producto de algo de naturaleza externa. Podrá entonces atribuirlo a una respuesta inadecuada del medio a sus necesidades, que modificó y perturbó profundamente su existencia, y no a su enfermedad o a su fatídico destino. La nueva versión de aquel desgraciado hecho del pasado en el tratamiento hará surgir en él algo que recién ahora puede identificar como odio, un odio justificado o razonable. El odio justificado irá dirigido a otro, el terapeuta, quien lo tolera, no responde con la misma moneda y le demuestra que ese odio no es arrasador, ya que puede sobrevivir a él y mantenerse incambiado (Winnicott, 1993a, 1993b, 1999a).

Después de experiencias de este tipo se instala definitivamente en cualquier paciente una clara discriminación, antes no totalmente alcanzada, entre lo de adentro y lo de afuera, entre lo yo y lo no-yo, entre el yo y el tú. Surgirán también dos nuevos ámbitos bien diferenciados: el de la fantasía — una realidad de carácter íntimo y muy personal- y el de la objetividad — una realidad distinta, de carácter predominantemente compartido- - Si este proceso no tiene lugar, el resultado es la retraumatización del paciente, quien reaccionará como lo hizo originalmente, con defensas falso self. Este es un resultado iatrogénico indeseable que genera la pérdida de la autenticidad, de la espontaneidad y del gusto por la vida. Predominará en el paciente la sumisión, el acatamiento a lo socialmente aceptable y, en definitiva, una adaptabilidad que traiciona la mismidad y se parece a una «muerte en vida» (Winnicott, 1993a).

Para terminar, compartimos algunos versos del poema Relaciones, de Little (2017, pp. 305-307). Ellos sintetizan en clave poética algo de lo que nos interesó plantear y compartir en este trabajo: la presencia inevitable en cada uno de nosotros de montos variables de odio y agresividad y su cualidad alternante y complementaria con el amor. Este todo complejo resuena poderosamente en la voz de la autora, una psicoanalista y paciente fuera de serie: 
Nuestros ritmos de amor y odio están descoordinados.

Por eso cada uno molesta al otro, aunque amamos.

$$
[\ldots]
$$

Entonces, aquí y allá, los dos son uno.

Y aquí y allá cada uno es dos;

$$
\text { [...] }
$$

Un frenesí alternante

$$
\text { [...] }
$$

De acción, interacción y reacción.

Nuevas fuerzas nacen y florecen:

nace un nuevo fuego, risas y lágrimas,

una nueva creación y nacimiento.

Margaret Little

\section{REFERENCIAS BIBLIOGRÁFICAS}

Bollas, C. (1991). La sombra del objeto. Buenos Aires: Paidós.

FREUD, S. (1991). Más allá del principio del placer. En Obras completas (vol. xviII, pp. 1-62). Buenos Aires: Amorrortu.

Little, M. (1995). Relato de mi análisis con Winnicott. Angustia psicótica y contención [1985]. Buenos Aires: Lugar Editorial. 
LitTLE, M. (2017). «R». La respuesta total del analista a las necesidades del paciente. En R. Rojas y L. Tuane (trads.), Transferencia neurótica y transferencia psicótica (pp.95-134) [1957]. Santiago de Chile: Pólvora. WinnicotT, D. W. (1989). Los bebés y sus madres [1987]. Buenos Aires: Paidós. Winnicott, D. W. (1990a). La agresión y sus raíces [1939]. En Deprivación y delincuencia (pp.104-112). Buenos Aires: Paidós.

Winnicott, D. W. (1990b). Las raíces de la agresión [1964]. En Deprivación y delincuencia (pp.113-120). Buenos Aires: Paidós.

Winnicott, D. W. (1991a). El miedo al derrumbe [1963]. En C. Winnicott, R. Shepherd y M. Davis (comps.), Exploraciones psicoanaliticas I (pp.111-121). Buenos Aires: Paidós.

WinnicotT, D. W. (1991b). El uso del objeto y el relacionarse mediante identificaciones [1968]. En C. Winnicott, R. Shepherd y M. Davis (comps.), Exploraciones psicoanaliticas I (pp.263-273). Buenos Aires: Paidós.

Winnicott, D. W. (1991c). El uso del objeto en el contexto de Moisés y la religión monoteísta [1969]. En C. Winnicott, R. Shepherd y M. Davis M (comps.), Exploraciones psicoanaliticas I (pp.287-293). Buenos Aires: Paidós.

WinnicotT, D. W. (1993a). La contratransferencia [1960]. En Los procesos de maduración y el ambiente facilitador (pp.207-216). Buenos Aires: Paidós.

Winnicott, D. W. (1993b). Análisis de los fines de la guerra. En El hogar, nuestro punto de partida. Ensayos de un psicoanalista (pp.243-244). Buenos Aires: Paidós.

Winnicott, D. W. (1999a). El odio en la contratransferencia [1947]. En Escritos de pediatría y psicoanálisis (pp.263-274). Buenos Aires: Paidós. 
WinnicotT, D. W. (1999b). La agresión en relación con el desarrollo emocional [1950]. En Escritos de pediatría y psicoanálisis (pp.275-293). Buenos Aires: Paidós.

Winnicott, D. W. (1999c). Aspectos metapsicológicos y clínicos de la regresión dentro del marco psicoanalítico [1954]. En Escritos de pediatría y psicoanálisis (pp.371-390). Buenos Aires: Paidós. 


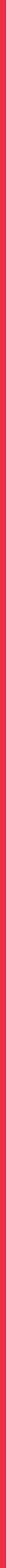

